\title{
Presenting features and treatment outcomes of chronic lymphocytic leukaemia in a resource poor Southern Nigeria
}

\section{Anazoeze Jude Madu' ${ }^{1}$ Kaladada Korubo², Augustine Okoye $^{3}$, Ifeoma Ajuba ${ }^{4}$, Augustine N. Duru ${ }^{1}$, Angela O. $\mathrm{Ugwu}^{1}$, Oji Nnachi ${ }^{3}$, Helen Chioma Okoye ${ }^{1}$}

1. Department of Haematology and Immunology, University of Nigeria Enugu Campus

2. Department of Haematology, University of Port Harcourt

3. Department of Haematology, Federal Teaching Hospital Abakaliki

4. Department of Haematology Nnamdi Azikiwe University, Nnewi, Anambra State

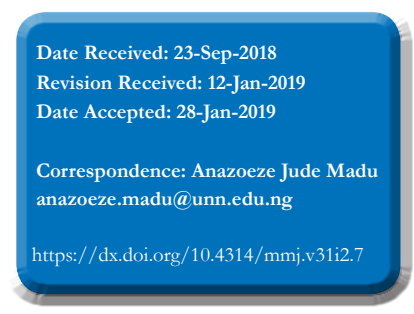

\section{Background}

Chronic lymphocytic leukaemia is a relatively common haematological malignancy affecting older adults, accounting for about $20 \%$ of haematological malignancies in Nigeria. Diagnosis of this disease depends on the demonstration of clonal lymphocytosis $>5 \mathrm{x} 109 / \mathrm{L}$ with a characteristic immunophenotypic pattern amidst other clinical and laboratory features.

Objectives

To determine the predominant clinical and laboratory features of CLL at presentation and their relationship with patient survival. This study also aims at examining the relationship between treatment protocol and outcome.

Methods: This is a retrospective study with 8 years data (2010-2018)collected from four different centers. Data was analyzed using SPSS 20.0.

Results

There were a total of 97 cases, with a male: female ratio of 1.1:1. The median age at presentation was 59 years. Approximately $55 \%$ of the patients presented at Binet stage $\mathrm{C}$, with splenomegaly in $93.2 \%$ and $78 \%$ were anaemic. The mean white cell count was 137.9 $\pm 14.7 \times 109 / \mathrm{L}$, with a median absolute lymphocyte count of $86 \times 109 / \mathrm{L}$. The commonest treatment regimen was chlorambucil and prednisolone and males had a superior response. The number of chemotherapy cycles, serum alkaline phosphatase and aspartate transaminase correlated positively with duration of survival. Mortality rate over the five year period was $14.3 \%$.

\section{Conclusion}

CLL was found to present in younger patients when compared to previous studies with a median age of 57 years at diagnosis. Our study showed a slight female preponderance and better response to therapy in males. Majority of the patients presented in Binet stage $\mathrm{C}$ and were treated with chlorambucil-based drug combinations compared to more current treatment with Fludarabine-based combinations. A high serum alanine transaminase and alkaline phosphatase was found to positively correlate with survival amongst this patient population

\section{Introduction}

Chronic lymphocytic leukaemia (CLL) is a monoclonal proliferation of mature-looking B lymphoid cells with attendant peripherallymphocytosis. This malignancy accounts for $17-20 \%$ of all haematological malignancies in Nigeria. It is the second most common haematological malignancy after diffuse large B-cell lymphoma, with $2-6$ per 100,000 new cases diagnosed annually $y^{4}$. The prevalence of CLL has been found to be $18.2 \%$ of all lymphoid malignancies. ${ }^{5}$ In other studies done in some countries with low socioeconomic status there has been an observed paucity of diagnostic capacity and lack of novel treatment options. The incidence varies widely across geographical locations, with Asia having a 5-10 fold lower prevalence. ${ }^{6}$ This indicates the possible role of genetic factors offering a protective role in Asians, as migrated Asians in western countries also have a reduced incidence of CLL. ${ }^{7}$ The higher prevalence in the resource limited countries, not withstanding their lower diagnostic capacity is more in support of a possible genetic aetiopathogenesis.

The malignancy is commoner in males, mostly seen in the elderly (age $>65$ years) with some familial tendency being alleged. ${ }^{\mathrm{d}, 8}$ Clinical presentation varies widely with some patients being diagnosed incidentally during a routine full blood count check. Staging of the tumor is usually done at diagnosis, using the system described by Rai et al or Binet et al, ${ }^{9}$ both of which are used for prognosis and decision on the commencement of therapy. Bone marrow trephine biopsy is also done to obtain a higher cell yield for cytogenetic studies and recently is being proposed for monitoring of minimal residual disease. ${ }^{10,11}$ Immuno-phenotyping is important to ascertain the monoclonality of the malignant cells as well as differentiate the $\mathrm{T}$ from the $\mathrm{B}$ cell malignancies. The malignant cells in CLL show co-expression of CD5, a T cell marker and CD $19^{12,13}$ and levels of monoclonal B cell above $5 \times 10^{9} / \mathrm{L}$ is considered diagnostic ${ }^{10,14}$.

The malignant cells in CLL have been found to have undergone somatic hypermutation (antigenic stimulation in the germinal centers) and include both the memory and marginal zone B cells. ${ }^{15}$ CLL cells over-express Bcl-2, an anti-apoptotic protein which is thought to immortalize the malignant clone. There appears to be a dependence of CLL 
cells on the bone marrow microenvironment because CLL cells in suspension culture undergo spontaneous apoptosis in vitro, except when co-cultured with bone marrow stromal cells ${ }^{16}$. These cells also express (immunoglobulin heavy chain variable region genes) IGHV as well as restricted subsets of $\mathrm{B}$ cell receptors to a larger extent than the normal mature $\mathrm{B}$ cells. These findings suggest that antigenic stimulation plays an important role in the pathogenesis of CLL. DNA sequencing studies have also detected mutated genes; MYD88, NOTCH1, SF3B1 and XPO1, all of which are thought to be of prognostic importance ${ }^{17}$. Other important biological markers include, lymphocyte doubling time, ZAP70 ${ }^{18,19}, \mathrm{CD}^{2} 8^{20}$, serum $\beta-2$ microglobulin ${ }^{21}$, thymidine kinase as well as presence of other cytogenetic abnormalities. There exists a remarkable paucity of investigative facilities to attain this depth of investigation for most patients in resource poor settings.

Management protocol for treatment of CLL includes combination of immunotherapy and standard chemotherapy for patients with symptomatic, advanced or progressive disease. While for patients with stable disease the "watch and wait" algorithm is usually deployed. In the past chlorambucil with or without steroids was the gold standard for management of CLL ${ }^{9}$. This was been replaced by more efficient combinations involving the use of bendamustine, fludarabine, cladribine, alemtuzumab (recombinant antiCD52) and rituximab (anti-CD20 monoclonal antibody) ${ }^{22}$. However, these current first line drugs are quite expensive and not easily available in the economically disadvantaged parts of the world where treatment is largely still chlorambucil/ cyclophosphamide-based. This study is aimed at describing the predominant clinical and laboratory features of CLL and their relationship with patient survival. We also intend to examine the relationship between treatment protocol and outcomes / survival achieved in this milieu of sub-optimal care.

\section{Patients and Methods}

Clinical data was obtained from the case notes of 97 patients diagnosed with CLL at the University of Nigeria Teaching Hospital, Ituku-Ozalla, University of Port Harcourt Teaching Hospital, Nnamdi Azikiwe University Teaching Hospital, Nnewi and Federal Medical Center Abakaliki, all in Nigeria. Data obtained were age, sex, Binet stage, spleen size, hepatic and renal function tests, haematological parameters and chemotherapeutic regimen used as well as the duration from the date of diagnosis to when the patient was last seen. This was done for all patients diagnosed between June 2010 and July 2018, using the patients' case notes, in the wards and clinics, as well as the admission registers from the four different participating hospitals. This was done retrospectively for the patients seen prior to 2015 and prospectively for the patients seen up till July 2018. A pre-designed excel data sheet was used for uniform data collection from the participating centers.

\section{Statistics}

Data was analyzed using SPSS20.0 (Illinois, Chicago) and expressed in tables and figures. The Kaplan Meier survival curve and equation was used to assess survival differences between groups. Spearman Rho and Kendaull_taub were employed to assess correlation and the value $<0.05$ were assumed to be significant.

\section{Results}

Ninety seven patients were diagnosed and treated for CLL in the 4 centers within the 8 year interval. Their ages ranged from 29 to 89 years with a median age of 59 years and a mean age of 60 years. These consisted of $50(51.5 \%)$ males and $47(48.5 \%)$ females, giving a male: female ratio of 1.1:1. Majority, $53(54.6 \%)$ of the patients were of Binet Stage $\mathrm{C}$ at diagnosis, while $11.3 \%$ and $5.2 \%$ of them presented with Binet Stage B and A, respectively. Splenomegaly was observed in $93.2 \%$ of the patients and the spleen size ranged from 0 to $36 \mathrm{~cm}$ below the left costal margin, with a median value of $14 \mathrm{~cm}$.

\section{Clinical and Laboratory Aspect}

The median value of the total white cell count at diagnosis was found to be $93.5 \times 10^{9} / \mathrm{L}$, while the mean value was $137.9 \pm 17.1 \times 10^{9} / \mathrm{L}$. The median absolute lymphocyte count was $86 \times 10^{9} / \mathrm{L}$, with a mean value of $136.5 \pm 22.7 \times$ $10^{\circ} / \mathrm{L}$. The mean $\mathrm{Hb}$ at diagnosis was $8.5 \pm 0.3 \mathrm{~g} / \mathrm{dL}$ with a median of $8.8 \mathrm{~g} / \mathrm{dL}$. Seventy-eight percent of the patients were anaemic at diagnosis $(\mathrm{Hb}<10 \mathrm{~g} / \mathrm{dL})$, while $31.5 \%$ were thrombocytopaenic (platelet count $<100 \times 10^{9} / \mathrm{L}$ ). There was no direct relationship between $\mathrm{Hb}$ at presentation and the duration of management/ survival, $\mathrm{p}=0.053$ (correlation coefficient 0.224). The Binet stage was also found to be associated with the $\mathrm{Hb}$ at diagnosis (coefficient 0.359, $\mathrm{p}=0.001$ ), spleen size (coefficient 0,275, $\mathrm{p}=0.014$ ), leucocyte count at diagnosis (coefficient 0.215, $\mathrm{p}=0.032$ ), absolute lymphocyte count (coefficient 0.303, $\mathrm{p}=0.007$ ), platelet count at diagnosis (coefficient 0.236, $\mathrm{p}=0.028$ ) and alkaline phosphatase (coefficient 0.312, $\mathrm{p}=0.019$ ). Coombs test was positive in only 2 patients out of 62 tested while none of the patients were HIV positive. Majority of the patients (93/97) had CLL while only 4 of them had CLL/ PL. The haematological parameters as well as some of the clinical features of the patients on presentation is shown on Table 1.

\section{Table 1.Clinical and laboratory parameters at presentation and their correlation with survival in CLL patients}

\begin{tabular}{|c|c|c|c|c|}
\hline Parameter & $\mathrm{N}$ & Mean & Median & $\begin{array}{l}\text { Coefficient } \\
\text { ( } p \text { value) }\end{array}$ \\
\hline Age (years) & 97 & 60 & 59 & $0.065(0.547)$ \\
\hline $\begin{array}{l}\text { H a e m o g l o b i i } \\
\text { concentration }(\mathrm{g} / \\
\mathrm{dL})\end{array}$ & 80 & 8.5 & 8.8 & $0.224(0.053)$ \\
\hline $\begin{array}{l}\text { Leucocyte count }(x \\
\left.10^{9} / \mathrm{L}\right)\end{array}$ & 84 & 137.9 & 93.5 & $\begin{array}{l}-0.079 \\
(0.463)\end{array}$ \\
\hline Spleen size $(\mathrm{cm})$ & 59 & 16 & 14 & $\begin{array}{l}-0.031 \\
(0.813)\end{array}$ \\
\hline $\begin{array}{l}\text { A b s o I u } t \text { e } \\
\text { Lymphocyte count } \\
\left(x \quad 10^{\circ} / L\right)\end{array}$ & 57 & 136.5 & 86 & $\begin{array}{l}-0.139 \\
(0.228)\end{array}$ \\
\hline $\begin{array}{l}\text { Platelet count } \\
\text { (× 10\%/L) }\end{array}$ & 73 & 146 & 132 & $0.105(0.391)$ \\
\hline
\end{tabular}


Figure la shows a bar chart of the spleen size and $\mathrm{Hb}$ in males versus females. Figurelb shows the distribution of absolute lymphocyte count and serum alkaline phophatase amongst the patients in the different Binet stages. This liver enzyme also showed a significant relationship with both the duration of management/ survival and the number of chemotherapy cycles given. $(p=0.003$ and 0.041 , respectively).

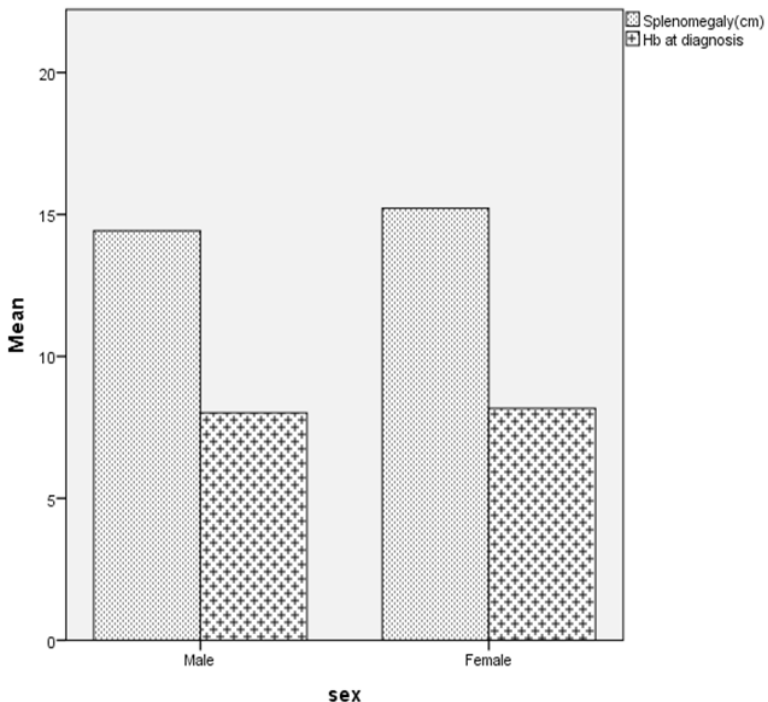

Fig 1a

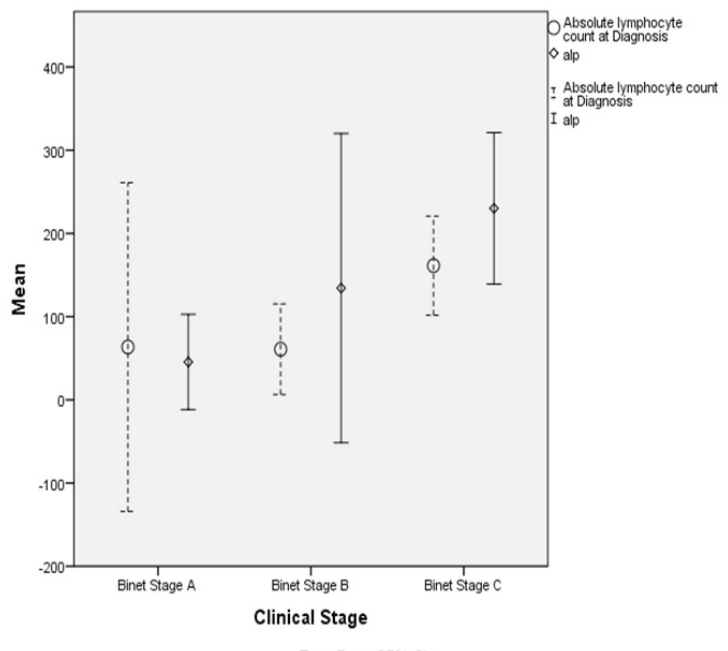

Fig $1 b$

\section{Treatment Outcomes}

Majority of the patients (43.1\%) were on chlorambucil and prednisolone $(\mathrm{Chl}+\mathrm{P}), 27.6 \%$ on cyclophosphamide/ vincristine/ prednisolone (CVP) and $8.6 \%$ cyclophosphamide/ prednisolone $(\mathrm{C}+\mathrm{P})$ while $2.1 \%$ were placed on cyclophosphamide/ hydroxodaunorubicin/ vincristine/ prednisolone (CHOP). The drug regimen used was switched in $27.2 \%$ of the patients and the reason was mainly due to poor response to chemotherapy (nonresponse, relapse and resistance). The median duration of management was 4 months and ranged from 0 to 72 months, this was found to show a significant positive correlation with the number of cycles of chemotherapy, alanine transaminase and aspartate transaminase levels $(\mathrm{p}=0.0001,0.013$ and 0.004 , respectively)
Figure 2 (a-d) shows the Kaplan-Meier survival curve for males versus females as well as individuals who received varying chemotherapeutic combinations.

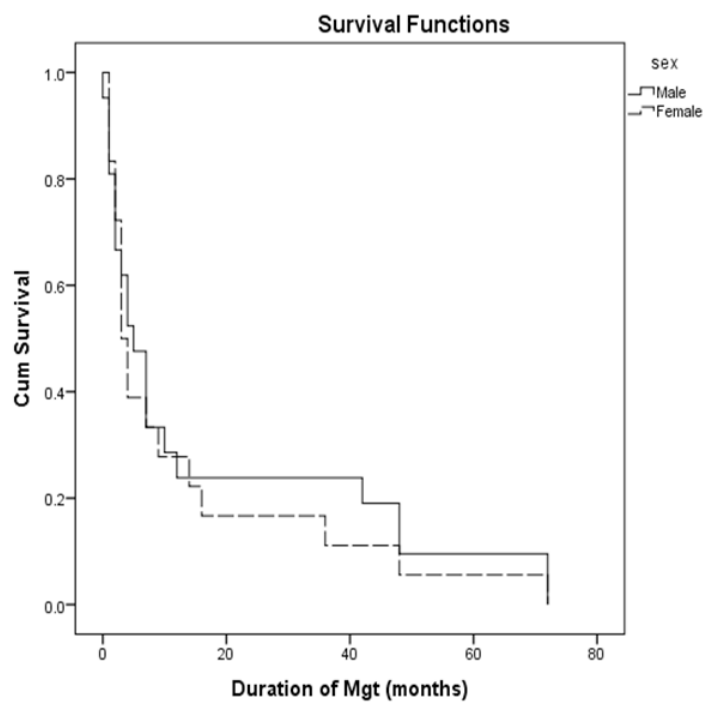

Fig 2a

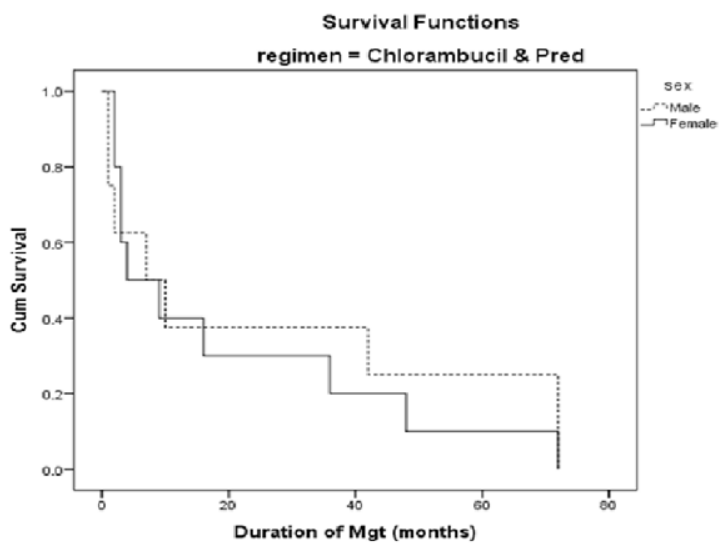

Fig 2b

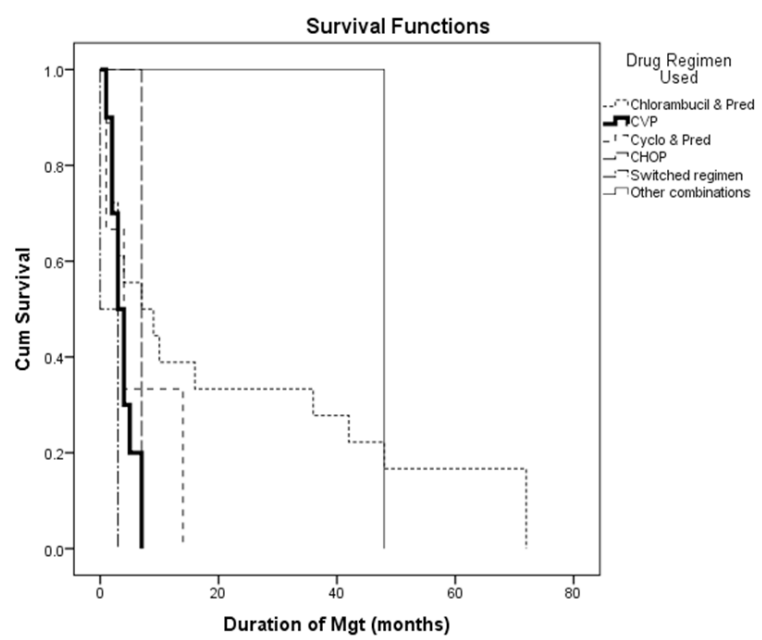

Fig 2c 


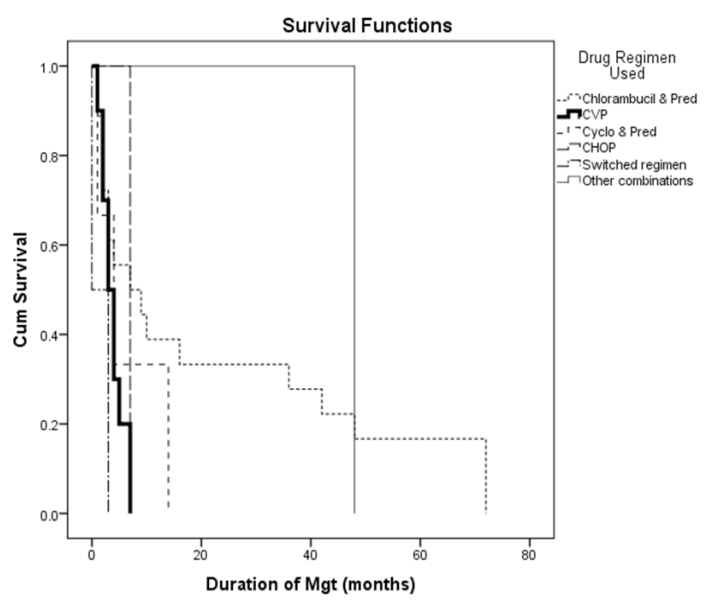

Fig 2d

The most common co-morbidity in these patients was diabetes mellitus which was observed in $28 \%(5 / 18)$ of the patients. This is followed by peptic ulcer disease in $17 \%$ $(3 / 18)$. Complications observed in patients on treatment included; skin eruptions (pemphigus and shingles inclusive) - 12\% (3/25), anaemia $-20 \%$ (5/25), respiratory tract infections (including 2 cases of Tuberculosis) - 16\% (4/25). However in the majority $(70 \%)$ of the patients where these were recorded no complication of the treatment or primary disease was noted. The duration of management/ survival was influenced by neither the total white cell count nor the absolute values. $(\mathrm{p}=0.463$ and $\mathrm{p}=0.228$, respectively). Males showed superior survival rates between the $10^{\text {th }}$ and $48^{\text {th }}$ month post-diagnosis compared to females. At the time of this report 8 ( 5 females and 3 males) of the patients had been reported dead representing mortality rate of $14.3 \%$ and $76.4 \% 5$-year survival.

\section{Discussion}

Malignancies are driven by genetic mutations, which confer some variability in clinical presentation as well as response to treatment. Patients in this study presented at a mean age of 59 years and this is similar to what was observed by Salawu et al in Ile-Ife ${ }^{23}$, while older age groups have been predominantly affected in the Europe and United States ${ }^{24}$. This however implies that a younger age group is affected by CLL in Nigeria, thus the need for further investigation into the predominant mutations causing this leukaemia in these patients. This may also be explained by the recent finding of monoclonal B lymphocytosis with increasing age ${ }^{25}$, considered against the wide gap in life expectancy across the 2 patient populations. The male: female ratio in our study shows a slight male preponderance although previous studies have shown either a slight male or female predominance. Even though we may not be technologically advanced in terms of diagnostics making for possible misdiagnosis, this may imply that there may not be any actual difference in prevalence across the sexes. Majority of patients presented in Binet stage $\mathrm{C}$, this is understandable, as in most cases lymphocytosis is discovered as an incidental finding from a blood count done for other reasons. However the staging system is dependent on the haemoglobin concentration; a decreasing level of which this study shows to negatively affect survival. In other Nigerian studies higher lymphocyte count was found to favor survival ${ }^{23}$; however this was refuted by our study, where no association was observed. It is known that the degree of splenomegaly, lymphadenopathy as well as lymphocyte counts are indirect measures of tumor bulk and are expected to hamper longevity. However, our study did not reveal this and this may be due the presence or absence of other prognostic markers like ZAP70 and CD38 which are not routinely assessed in CLL patients in low and middle income countries (LMICs). The serum alkaline phophatase at diagnosis showed a positive correlation with the duration of survival. The clinical significance of this finding is currently unknown but requires further investigation as it may provide a future laboratory prognostic marker which can be easily assessed in resource limited settings. Disease presentation at a younger age was found to be associated with progressive disease and by extension, reduced survival. This may be due to the occurrence of a different mutation in the younger CLL patients which may connote more aggressive disease phenotype ${ }^{6,26}$. CLL in the elderly might actually be "genotypically" different from CLL in the younger adults ${ }^{26,27}$. Chlorambucil-based regimen was used for majority of the patients in this study. Recently re-classification of CLL patients has become necessary with the advent of the disease entity - clinical monoclonal B- lymphocytosis, depending on the B cell count ${ }^{28}$. Majority of the centers in LMICs do not further differentiate their CLL patients based on this criterion and might possibly lump both patient groups together. None of the patients were placed on fludarabine or rituximab, both of which, though considered standard of care $^{22}$, are quite expensive and cannot be afforded by most patients in LMICs. The median duration of followup was 4 months and this portrays the lack of adequate documentation and patient tracking systems. Of the various chemotherapeutic combinations used in the patients in this study, patients on chlorambucil/prednisolone were shown to have longer duration of survival. This indicates that this combination is still the best of what is available although patients are more likely to benefit from using the more standard combinations. Patients treated with fludarabine/ cyclophosphamide/rituximab, (FCR) combination has been known to achieve deeper remission to the extent of eliminating minimal residual disease ${ }^{10,11}$. This treatment target is usually unachievable with the treatment regimen in use in LMICs. Better therapeutic options have to be explored for the CLL patients in resource-limited settings in order to optimize their life expectancy. Unlike other studies ${ }^{29,30}$, males were shown to have superior survival rates compared to females. The reason for this variation is not known and will require further research.

\section{Limitations of the study}

This being a retrospective study was hampered by poor documentation, and missing data/incomplete data. This has affected the depth of the study.

\section{Conclusion}

CLL was found to affect the younger patients in this study with a median age at presentation being of 59 years. There was significant association between the serum alkaline phophatase levels at diagnosis and the duration of management/survival in the CLL patients studied. Majority of the patients received chlorambucil and prednisolone, while none received fludarabine-based treatment, with a median duration of 4 months follow-up. This portrays sub- 
optimal treatment response with an underlining poor patient documentation and tracking system.

\section{Acknowledgements}

We acknowledge the resident doctors in the different institutions who helped in data collection.

\section{Funding}

No funding received.

\section{Ethical considerations}

Ethical approval for this study was obtained from the research and ethics unit of the college of Medicine, University of Nigeria, Enugu campus. Authors declare no conflict of interest

\section{References}

1. Omoti CE and Olatunji Imiere E. Trends in the Pattern of Leukaemia Incidence in a Tertiary Health Center in Nigeria: 1990-2004. Journal of Medicine and Biomedical Research, Vol. 5, No. 2, December 2006;5(2):44-9. doi: jm06019.

2. Statistics of hematologic malignancies in Korea: incidence, prevalence and survival rates from 1999 to 2008. Park HJ, Park E, Jung K, Kong H, Won Y, Lee JY, et al. Korean J Hematol. 2012 Mar;47(1):28-38. doi. org $/ 10.5045 / \mathrm{kjh} .2012 .47 .1 .28$

3. Korubo KI, Okoye HC, CC Efobi CC. The economic burden of malignant and premalignant hematological diseases in Southern Nigeria. 2018 ; 21(11) : 1396-1402. DOI: 10.4103/njcp.njcp_278_18.

4. Nwannadi IA, Alao OO, Bazuaye GN, Halim NKD, Omoti CE. The Epidemiology of Haematological Malignancies at the University Of Benin Teaching Hospital: A Ten-Year Retrospective Study.The Internet Journal of Epidemiology. 2010 Volume 9 Number 2. DOI:10.5580/1 fbb

5. Omoti CE, Nwannadi AI, Obieche JC, Olu-Eddo AN. The epidemiological features of lymphoid malignancies in Benin City, Nigeria: a 15 years study. The Pan African Medical Journal. 2012;11:10. doi:10.11604/pamj.2012.11.10.403

6. Egesie OJ, Agaba PA, Silas OA, Achenbach C, Zoakah A, Agbaji O, et al. Presentation and survival in patients with hematologic malignancies in Jos, Nigeria: A retrospective cohort analysis. J Med Trop 2018;20:49 56. DOI: $10.4103 /$ jomt.jomt_8_18.

7.. Smith A, Howell D, Patmore R, Jack A, Roman E. Incidence of haematological malignancy by sub-type: a report from the Haematological Malignancy Research Network. $\mathrm{Br} J$ cancer 2011;105:1684-2. . doi: [10.1038/bjc.2011.450]

8. Tomeczkowski J, Leisten MK, Metin H, Khuen C, Fleischmann J, Tapprich C. Prevalence and Treatment of chronic lymphocytic leukaemia (CLL) In Germany: an analysis of sickness funds. Value in health the journal of the International Society for Pharmacoeconomics and Outcomes Research 2014;17:A524. DOI:10.1016/j.jval.2014.08.1645

9.Yang SM, Li JY, Gale RP, Huang XJ. The mystery of chronic lymphocytic leukemia (CLL): Why is it absent in Asians and what does this tell us about etiology, pathogenesis and biology? Blood Rev 2015;29:205-13. doi: 10.1016/j.blre.2014.12.001

10.. Slager SL, Zent CS. Genetic risk of chronic lymphocytic leukemia: a tale of two cities. Leukemia \& lymphoma 2014;55:735-6. doi: 10.3109/10428194.2013.840889.

11. Healey R, Patel JL, de Koning L, Naugler C. Incidence of chronic lymphocytic leukemia and monoclonal B-cell lymphocytosis in Calgary, Alberta, Canada. Leukaemia research. 2015; 39:429-434. doi: 10.1016/j.leukres.2015.01.015

12.. Michallet M, Sotto JJ, Moulin JJ, Arvieux J, Hollard D. Management of CLL patients after chlorambucil therapy. Special value of a second RAI staging. Eur J Cancer 1980;16:511-7.

13. Rawstron AC, Bottcher S, Letestu R, Villamor N, Fazi C, Kartsios H, et al. Improving efficiency and sensitivity: European research initiative in CLL (ERIC) update on the international harmonised approach for flow cytometric residual disease monitoring in CLL. Leukemia. 2013;27:142-9. doi: 10.1038/leu.2012.216

14. Strati P, Keating MJ, O’Brien SM, Burger J, Ferrajoli A, Jain N, et al. Eradication of bone marrow minimal residual disease may prompt early treatment discontinuation in CLL. Blood. 2014;123:3727-32. doi: 10.1182/blood-2013-11-538116

15. Kosmaczewska A, Ciszak L, Suwalska K, Wolowiec D, Frydecka I. CTLA-4 overexpression in CD19+/CD5+ cells correlates with the level of cell cycle regulators and disease progression in B-CLL patients. Leukemia. 2005;19:301-4.

16. Secchiero P, Tiribelli M, Barbarotto E, Celleghini C, Michelutti A, Masolini $\mathrm{P}$, et al. Aberrant expression of TRAIL in B chronic lymphocytic leukemia (B-CLL) cells. J Cell Physiol 2005;205:246-52.

\section{DOI:10.1002/jcp.20392.}

17. Molica S, Giannarelli D, Mirabelli R, Levato L, Gentile M, Lentini $\mathrm{M}$, et al. Changes in the incidence, pattern of presentation and clinical outcome of early chronic lymphocytic leukemia patients using the 2008 International Workshop on CLL guidelines. Expert Rev Hematol 2014;7:691-5. DOI:10.1586/17474086.2014.954542

18. Szepesi A. Molecular biology of CLL. Magyar onkologia 2005;49:327-30

19. Burger JA, Gribben JG. The microenvironment in chronic lymphocytic leukemia (CLL) and other B cell malignancies: insight into disease biology and new targeted therapies. Semin Cancer biol 2014;24:71-81. doi: 10.1016/j.semcancer.2013.08.011.

20. Te Raa GD, Derks IA, Navrkalova V, Skowronska A, Moerland PD, van Laar J, et al. The impact of SF3B1 mutations in CLL on the DNA-damage response. Leukemia 2015;29:1133-42. doi: 10.1038/ leu.2014.318.

21. Zanotti R, Ambrosetti A, Lestani M, Ghian P, Pattaro C, Remo A, et al. ZAP-70 expression, as detected by immunohistochemistry on bone marrow biopsies from early-phase CLL patients, is a strong adverse prognostic factor. Leukemia 2007;21:102-9. DOI:10.1038/ sj.leu. 2404458

22. Wiggers TG, Westra G, Westers TM, Abbes AP, Strunk A, KuipperKramer E, et al. ZAP70 in B-CLL cells related to the expression in NK cells is a surrogate marker for mutational status. Cytometry Part B. 2014;86:280-7. doi: 10.1002/cyto.b.21132.

23. Thompson PA, Tam CS. CD38 expression in CLL: a dynamic marker of prognosis. Leukemia \& lymphoma 2014;55:1-2. DOI:10.310 9/10428194.2013.789510

24. Shvidel L, Tadmor T, Braester A, et al. Pathogenesis, prevalence, and prognostic significance of cytopenias in chronic lymphocytic leukemia (CLL): a retrospective comparative study of 213 patients from a national CLL database of 1,518 cases. Ann hematol. 2013;92:661-7. DOI 10.1007/s00277-012-1663-3.

25. Jain N, O'Brien S. Initial treatment of CLL: integrating biology and functional status. Blood 2015; 126:463-470. doi: 10.1182/ blood-2015-04-585067.

26. Salawu L, Bolarinwa RA, Durosinmi MA. Chronic lymphocytic leukaemia: a-twenty-years experience and problems in Ile-Ife, SouthWestern Nigeria. Afr Health Sci 2010;10:187-92.

27. Klein U, Dalla-Favera R. New insights into the pathogenesis of chronic lymphocytic leukemia. Semin Cancer Biol 2010;20:377-83. doi: 10.1016/j.semcancer.2010.10.012

28. Landgren O, Albitar M, Ma W,Abbasi F, Hayes RB, Ghian P, et al. B-cell clones as early markers for chronic lymphocytic leukemia. N Engl J Med2009;360:659-67. doi: 10.1056/NEJMoa0806122.

29. Pepper C, Buggins AG, Jones CH, Walsby EJ, Forconi F, Pratt G, et al. Phenotypic heterogeneity in IGHV-mutated CLL patients has prognostic impact and identifies a subset with increased sensitivity to BTK and PI3Kdelta inhibition. Leukemia 2015;29:744-7. doi: [10.1038/leu.2014.308]

30. Swerdlow SH, Campo E, Pileri SA, Harris NL, Stein H, Siebert R et al. The 2016 revision of the world health organization classification of lymphoid neoplasms. Blood, 2016;127:2376-2390. doi: 10.1182/ blood-2016-01-643569. 
31. Molica S, Giannarelli D, Levato L, Mirabelli R, Gentilee M, Lentini $\mathrm{M}$, et al. A prognostic algorithm including a modified version of $\mathrm{MD}$ Anderson Cancer Center (MDACC) score predicts time to first treatment of patients with clinical monoclonal lymphocytosis (cMBL)/Rai stage 0 chronic lymphocytic leukemia (CLL). Int J Hematol 2014;100:290-95. doi: 10.1007/s12185-014-1634-7.

32. Molica S. Sex differences in incidence and outcome of chronic

lymphocytic leukemia patients. Leukemia \& lymphoma 2006;47:1477-
80. DOI:10.1080/10428190600555819

33. Catovsky D, Wade R, Else M. The clinical significance of patients' sex in chronic lymphocytic leukemia. Haematologica 2014;99:108894. doi: 10.3324/haematol.2013.101378. 